\title{
puente de la Muga
}

$565 \cdot 26$

E. TORROJA

emplazamiento: carretera general

año: 1939

Barcelona-Gerona

ingeniero: G. ANDREU

constructor: Omes

El mismo tipo de puente que el de Tordera puede hacerse con vigas de altura constante, como es el caso de otro puente sobre el río de la Muga. En éste, el proyecto preveía el lanzamiento longitudinal de las tres vigas-soldadas entre sí, unas a continuación de las otras-, como una viga continua de tres luces.

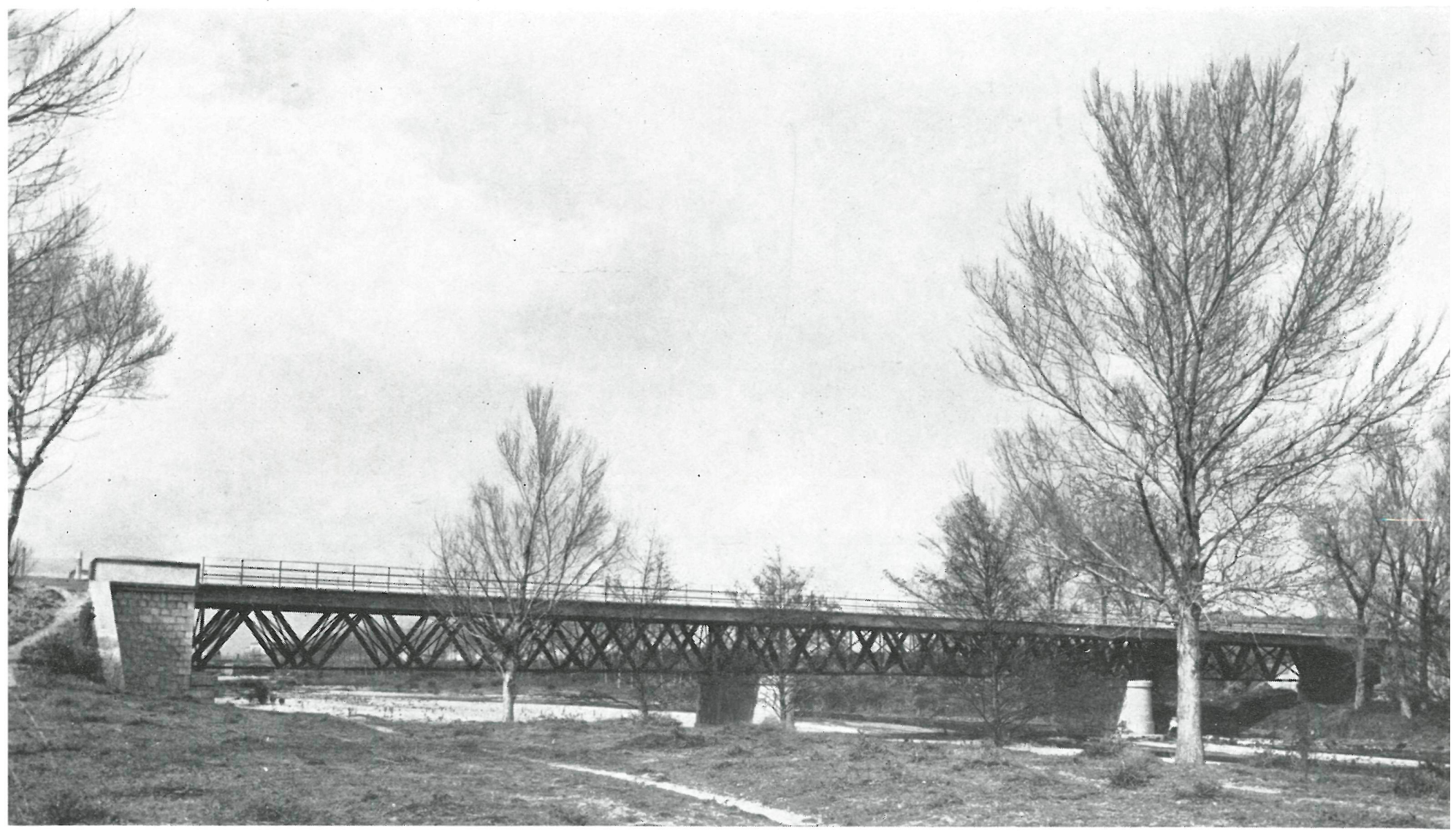

Después de colocadas sobre sus apoyos definitivos, se cortaron a soplete sus uniones para que trabajasen como vigas independientes simplemente apoyadas; y se hormigonaron los tableros de piso que forman sus cabezas de compresión. 

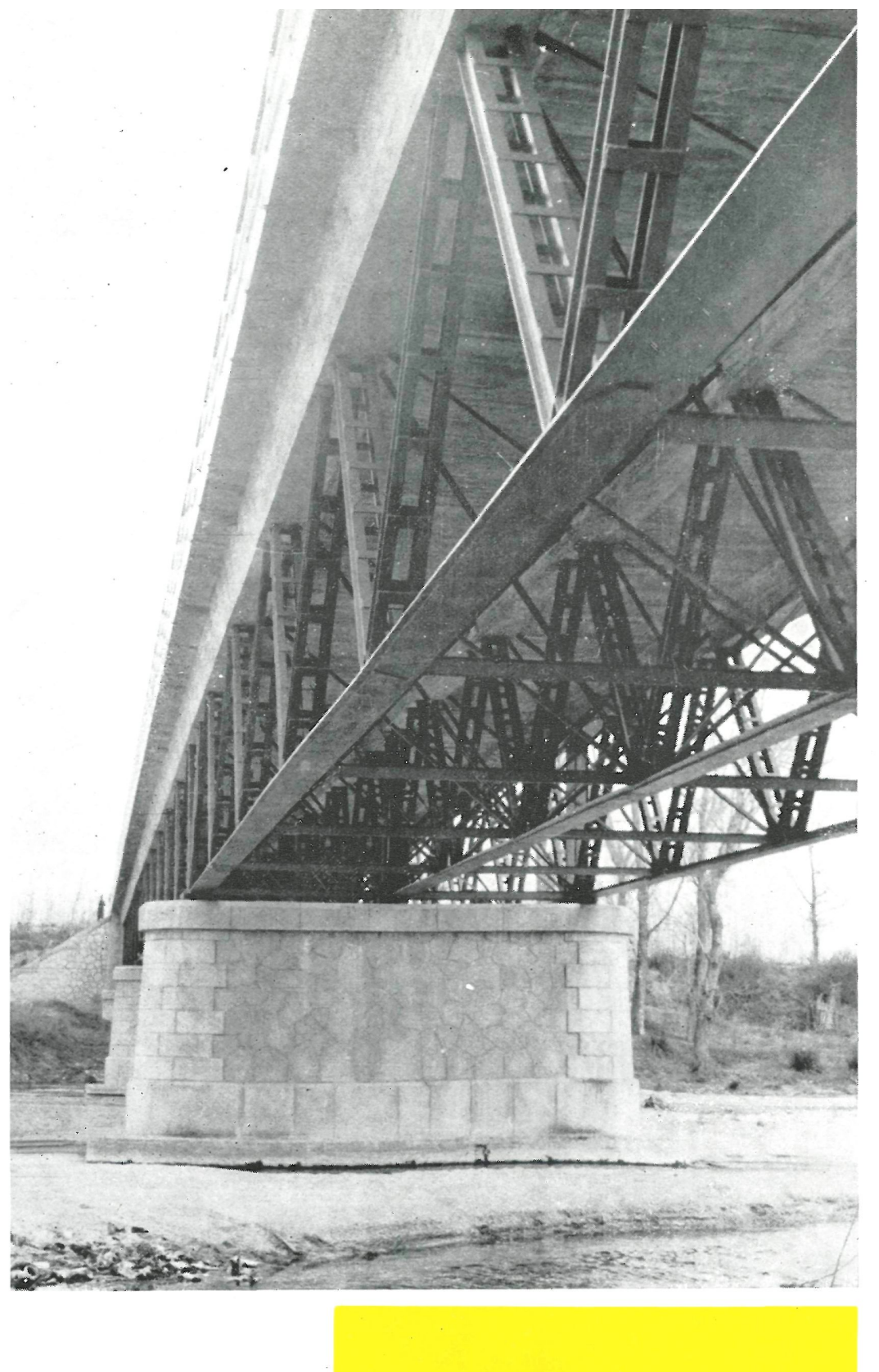

estinututum metrilica

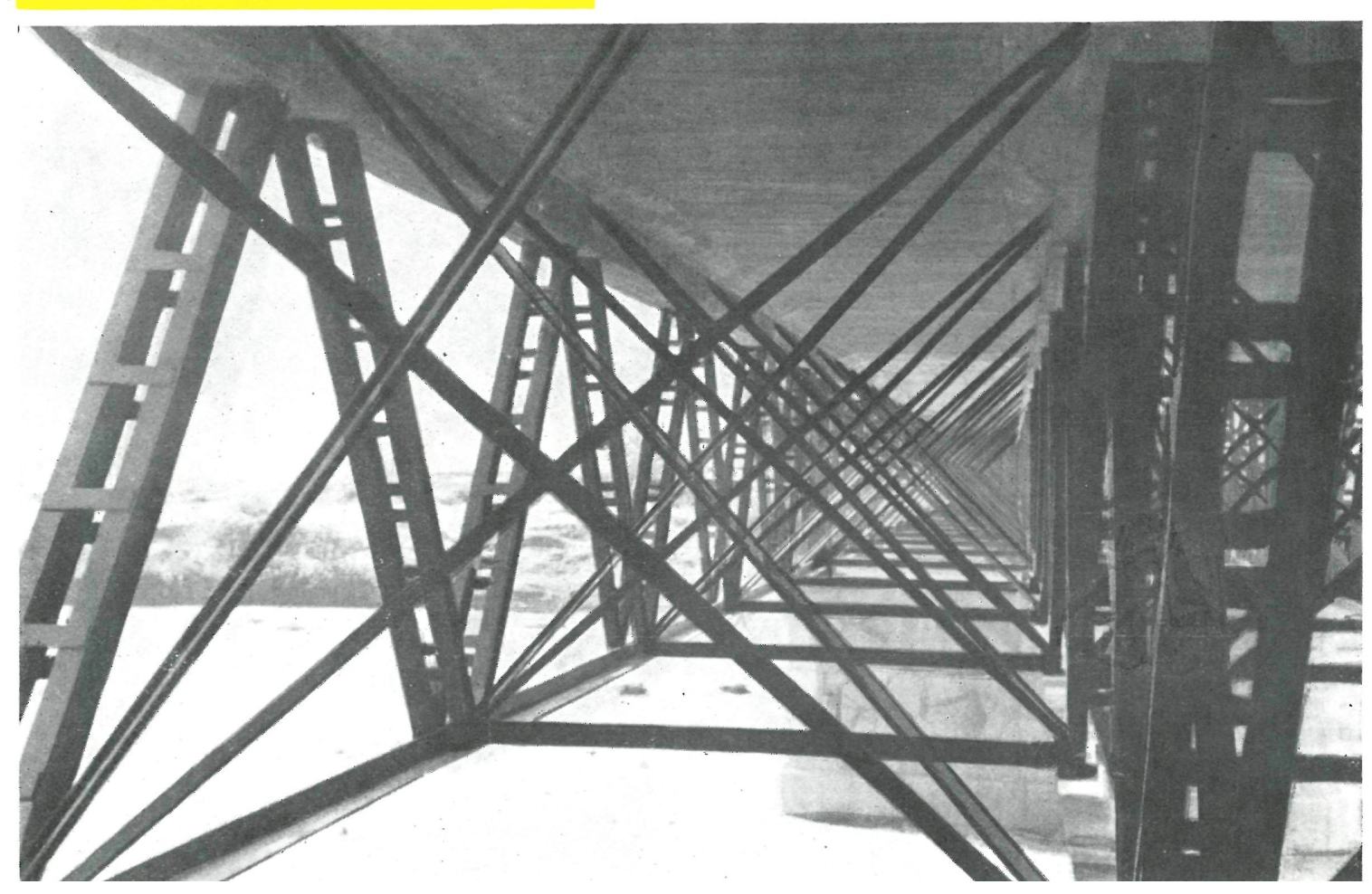

Indudablemente, podría hoy, con la seguridad que da la experiencia adquirida -y así lo haría si hubiese de proyectar otro puente de este tipo-, realizarse la viga continua sobre varios apoyos. Bastaría reforzar con hormigón armado la cabeza inferior, en la zona de momentos negativos sobre los apoyos, donde su peso produce flexiones de poca importancia. 


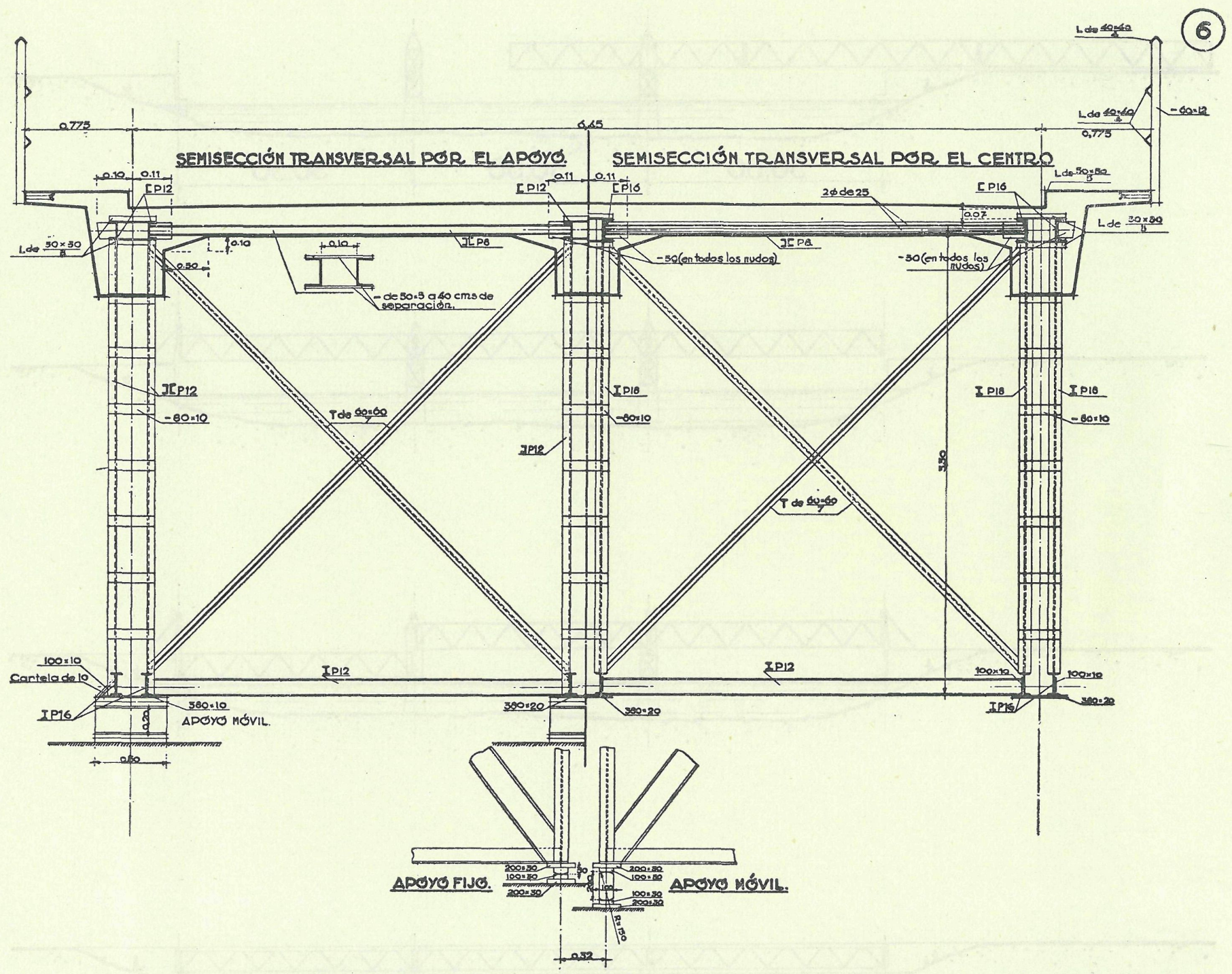

Secciomes frramsversediles

a님ㅇa

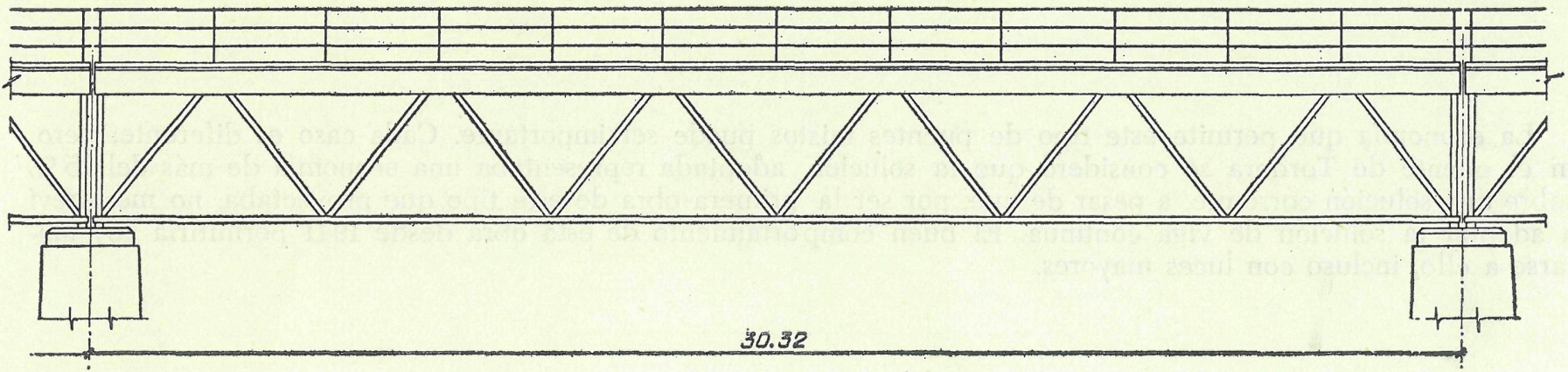



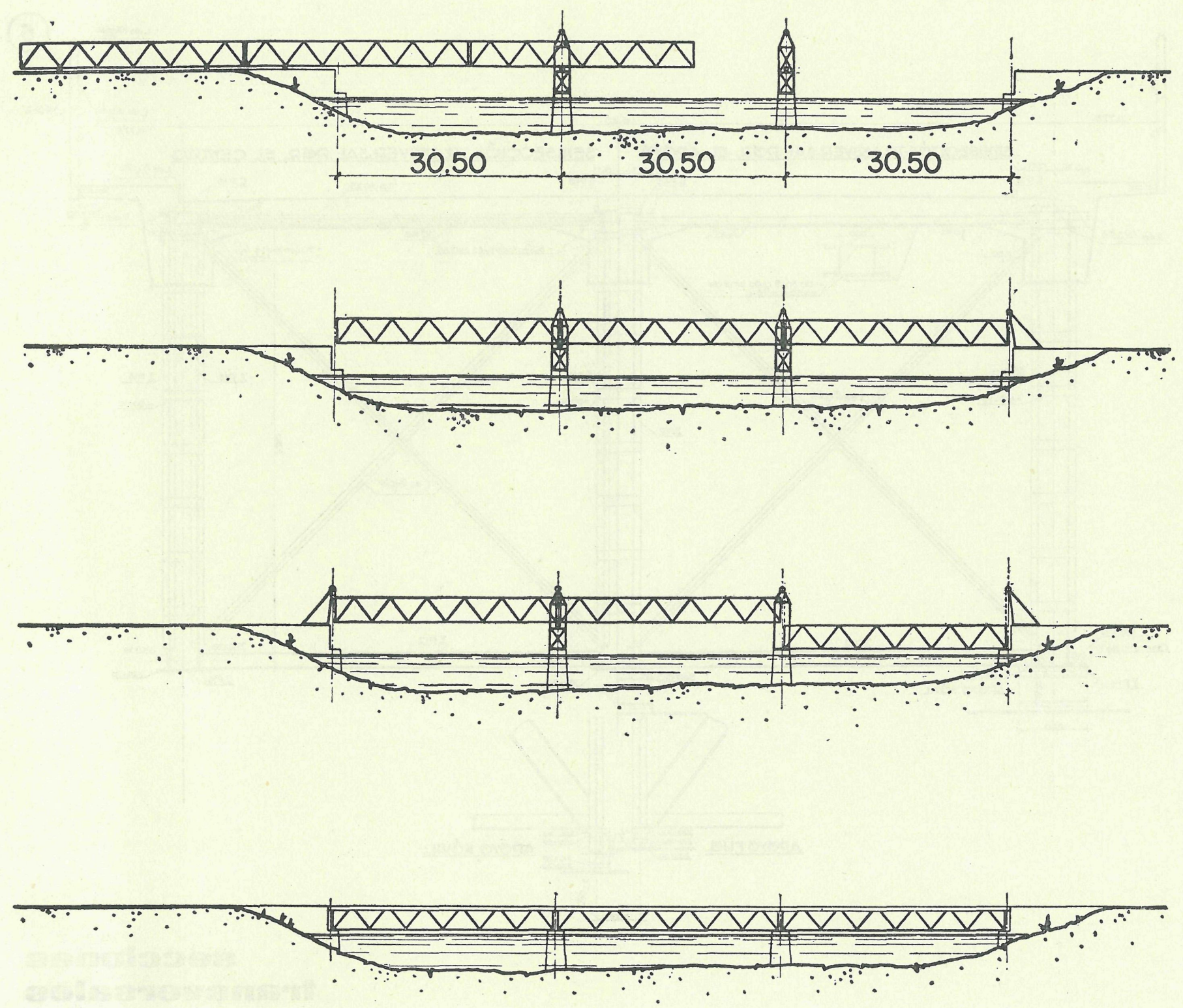

\section{fases \\ de lanzamiento}

La economía que permite este tipo de puentes mixtos puede ser importante. Cada caso es diferente; pero en el puente de Tordera se consideró que la solución adoptada representaba una economía de más del $25 \%$ sobre una solución corriente, a pesar de que, por ser la primera obra de este tipo que proyectaba, no me atreví a adoptar la solución de viga continua. El buen comportamiento de esta obra desde 1941 permitiría hoy lanzarse a ello, incluso con luces mayores. 